\title{
EL INCESANTE CANTO DEL GRILLO (DUELO Y ANGUSTIA EN SALAZAR HERRERA) ${ }^{1}$
}

\author{
Tatiana Herrera Ávila
}

\begin{abstract}
RESUMEN
Cuentos de angustias y paisajes, de Carlos Salazar Herrera, pone en escena el devenir constante del sujeto entre lo Real, lo Simbólico y lo Imaginario (Lacan), a través del afloramiento de la angustia, representada por el paisaje. "El grillo" muestra el posible encuentro del Indio José con lo Real, ante la angustia del Duelo, que se materializa en el eterno retorno del grillo. Este artículo expone que el desenlace del cuento es sólo una forma de escapar a ese Real, el cual es el inefable centro de todo relato, en torno al cual circula la cadena significante y se construye el sujeto.

Palabras clave: Literatura costarricense, Carlos Salazar Herrera, Cuentos de angustias y paisajes, Lacan.
\end{abstract}

\begin{abstract}
Cuentos de angustias y paisajes, by Carlos Salazar Herrera, shows the subject's constant coming and going trough the Real, the Symbolic and the Imaginary (Lacan), by means of the emerging anguish, represented by the landscape. "El grillo" shows the possible encounter between the Real and Indio José, triggered by the duel anguish, which materializes in the cricket's eternal recurrence. This article proposes that the ending of the short story is just a way to escape that Real, which is the ineffable center of every story, around which the significant chain moves and the subject is build.

Key words: Costa Rican Literature, Carlos Salazar Herrera, Cuentos de angustias y paisajes, Lacan.
\end{abstract}

El Dios Agni ha escalado las cimas del cielo, y liberándonos del pecado, nos ha liberado de la maldición. Athava Veda, 12,2

\section{Preludio interrogativo}

Carlos Salazar Herrera es un escritor que en nuestro medio no necesita presentación. Sin embargo, mencionaré, antes de comenzar, que incluso sus lectores contemporáneos le dieron el lugar que se merece. En 1947, cuando se publicó Cuentos de angustias y paisajes por

Tatiana Herrera Ávila. Licenciada en Filología Española. Profesora de Comunicación, Escuela de Estudios Generales de la Universidad de Costa Rica. San Pedro, San José, Costa Rica.

Correo electrónico: tatiana.herrera@yahoo.es 
primera vez, las reseñas críticas fueron muy favorables y encontraron en él resurgimientos del modernismo debido al preciosismo, así como rasgos clasicistas y una universalidad innegable.

De igual forma, todos los que alguna vez se han referido a este texto ${ }^{2}$ han encontrado en sus líneas un gran cromatismo y han resaltado el estilo pictórico -impresionista dirían algunos- que envuelve todos los cuentos. En efecto, cuando se lee cualquier cuento de Salazar Herrera, lo evocado es siempre una pintura, pero no en el sentido de cuadros de costumbres, sino literalmente en el de arte plástico, porque el tratamiento de cada palabra responde más a un pincel que a una pluma. Esto ha sido apabullante para la crítica y pareciera haber quedado tan impactada con el estilo de estos cuentos que, cegada por su perfección, ni siquiera ha intentado un análisis que no aborde cuestiones estilísticas.

Tal silencio me llamó la atención, por lo que decidí tratar de olvidar la maravilla de la sintaxis en Salazar Herrera y desviar mi mirada hacia los vacíos y las preguntas que el texto lanza en torno a la angustia y el dolor humanos. Cada cuento de angustias y paisajes es precisamente eso: una angustia y un paisaje que entran en relación en la psique de personajes, tal vez no muy reflexivos, pero sí muy elocuentes en sus acciones. Ésta será, pues, mi labor, motivada por un deseo de demostrar que Cuentos de angustias y paisajes nos habla de la complejísima condición humana y no se limita a las bellas descripciones harto resaltadas. Para llevar a cabo esto, me centraré en el cuento "El grillo", perteneciente a la mencionada colección.

"El grillo" nos presenta al indio José que, tras perder a su amada compañera, sufre la soledad y, mientras tanto, es torturado por el constante cantar de un grillo. El indio José se verá llevado al extremo de la desesperación, detonada por el dichoso grillo, y quemará su propio rancho, con el objetivo de destruir al incesante animal.

Como puede observarse, la diégesis del texto es bastante simple. No obstante, al leerlo una y otra vez, las preguntas empiezan a surgir: ¿cómo la presencia de un pequeño animalito puede generar en una persona tal crisis?, ¿qué era lo que le molestaba al indio José del grillo?, ¿qué relación guarda el insecto con la soledad de nuestro personaje?, ¿qué culpa tiene el grillo? A todas estas interrogantes trataremos de dar respuesta y, como veremos, al hacerlo,tendremos que deslizarnos por el fascinante mundo de la psique humana, con la ayuda del psicoanálisis.

\section{Los sufrimientos del indio José}

Veamos primero cuál es el estado emocional de nuestro personaje. Desde el inicio del cuento, sabemos que el indio José está solo:

El indio José había conseguido un lugar solitario en el ancho playón de la bahía, y entre los jícaros y los tamarindos armó su rancho (Salazar Herrera 1990: 61).

El lugar donde vive es también solitario. Así que la primera angustia a la que el indio José se enfrenta es la soledad, y esta angustia es compartida por el paisaje. Hay, así, una correlación entre las emociones del personaje y la manifestación del ambiente que lo rodea.

Otro elemento importante digno de tomarse en cuenta en este momento es que el cuento se inicia in media res; es decir, desde el principio nuestro personaje se verá molestado por la presencia del grillo y así, también desde el inicio, sabemos cuál es su crisis: 
-¡Tampoco voy a poder dormir esta noche!... ¡Ese grillo m’está volviendo loco! (61).

En este pasaje se evidencia ya la segunda angustia que aqueja al indio José: no puede dormir, es insomne. Lo que me interesa resaltar ahora es que el aparente motivo del insomnio es el grillo; sin embargo, poco después aparece otro elemento clave, él culpa de sus desgracias al rancho donde vive:

-¡Este rancho es una desgracia! -dijo, y dio un puñetazo en el tabique que hizo crujir la armazón (Salazar Herrera 1990: 61).

A lo largo del relato, el indio José hace una extraña relación entre la constante presencia del grillo y el rancho, como si éste provocara al grillo, e incluso llegará a decir repetidas veces que el rancho no lo quiere, lo que -como veremos más adelante- responde a una circunstancia en particular. Es importante resaltar, además, que es notable cómo el indio José desarrolla un deseo por destruir el rancho ya desde el inicio; es como una especie de aviso de lo que luego vendrá, es decir, una pequeña prolepsis.

\section{La eterna persistencia del grillo}

Dediquemos nuestra atención ahora al otro elemento clave en la historia: el grillo.

Como ya vimos, el grillo retorna una y otra vez, de manera que su relación con el tema del eterno retorno es evidente. El eterno retorno es una reduplicación perpetua de un mismo momento; el tiempo es idéntico, no transcurre y remite, por ello, al momento de completud anterior al lenguaje, donde no hay diferencia ni tiempo que transcurra, sino que se está en un instante único, completo, real y perfecto. No es sino hasta que se introduce el Lenguaje, la Ley representada por el Significante Paterno, que se inaugurará la falta, la diferencia y será cuando el tiempo empiece a transcurrir. El lenguaje marca el principio del tiempo: a partir de él hay un antes y un después. De esa forma se llega a la distinción, a la diferencia y así se funda el sujeto.

Sabemos gracias a Néstor Braunstein que la categoría del eterno retorno remite a lo Real, registro de la psique relacionado con el trauma y la pérdida primigenia fundante del sujeto. Lo Real está constantemente regresando, con la intención de saciar la falta; responde, pues, a la pulsión de muerte, y provoca necesariamente una angustia, porque representa la inminencia de la muerte psíquica:

\footnotetext{
La definición, ya canónica, de lo Real indica que siempre, insistentemente, vuelve a su lugar y que no deja de no escribirse. Eterno retorno de lo mismo (Braunstein 1993: 42).
}

Cuando el deseo se satisface y se completa la falta, la psique del sujeto deja de circular en lo simbólico y se detiene. Es así como el eterno retorno es una metáfora de lo Real: evidencia su presencia, su pulsión, la muerte, pues lleva al sujeto una y otra vez a ese momento anterior a la falta, donde la completud lo llenaba todo, donde no había sujeto. El eterno retorno y la amenaza del encuentro con lo Real provocan en el sujeto una gran angustia, como ya dijimos, porque lo Real corresponde a la muerte psíquica. El posible encuentro con lo Real -así como el eterno retorno- son, por esta razón, ominosos ${ }^{3}$. 
En el cuento de Salazar Herrera, el eterno retorno está representado por ese grillo ${ }^{4}$, que regresa una y otra vez, a tal punto que no deja dormir al indio José. El narrador describe al grillo de la siguiente forma:

Unos segundos después, volvió el chillido. Agudo. Obstinado. Intermitente (Salazar Herrera 1990: 61).

Esta descripción del grillo, por sinécdoque, a partir del ruido que hace, comprueba que dicho insecto representa el eterno retorno en el texto, pues es obstinado, regresa siempre, es intermitente, es decir se va y viene, y es agudo, intenso y molesto. Así, el grillo es señal de ese posible encuentro con lo Real.

\section{4. $\quad$ El duelo del indio José}

Es en este momento que llegamos al verdadero meollo del asunto, tal y como nos lo informa el propio narrador. El indio José, como sabemos desde el principio, está solo y, por ello, no tiene con quien hablar:

El indio José padecía de insomnio. A ratos caminaba y caminaba tras el sueño. A ratos se tendía en el tabanco y apretaba con rabia los párpados. Ya le echaba las culpas al grillo, ya le echaba las culpas al rancho. Finalmente se acercó, sin querer, al verdadero motivo de las angustias:

-iSi al menos tuviera con quién hablar! (Salazar Herrera 1990: 61)

A continuación, sabemos que el indio José es viudo. Su mujer murió en el parto. Esto hace que nuestro personaje sufra el duelo, hecho que lo convierte en un sujeto melancólico, tema ampliamente desarrollado por el psicoanálisis y que analizaremos a continuación.

Sin embargo, antes de proseguir, nos parece apropiado hacer un paréntesis para referirnos a la muerte de la compañera del indio José, con el fin de no dejar nada por fuera. El hecho de que ella muriera en el parto resulta muy sugerente. Cuando una mujer se convierte en madre, se vuelve una amante imposible, y muere -por así decirlo- como objeto de deseo para su compañero. La muerte de la compañera del indio José en el texto simboliza precisamente esa imposibilidad de que ella sea objeto de deseo para el indio José.

La teoría de Julia Kristeva resulta de mucha ayuda para comprobar lo anterior. Dentro de la cultura occidental, logocéntrica, judeocristiana y patriarcal, una madre no puede ser objeto de deseo. Por ello, el ideal de madre es la Virgen María, incapaz de tener deseo y de ser objeto de deseo de otro que no sea su hijo, al que ha tenido -inclusive- sin haber realizado el acto sexual. El único deseo que se le permite a la mujer es el deseo de ser madre:

El cristianismo es indudablemente la construcción simbólica más refinada en la que la femineidad, en la medida en que se transparenta -y se transparenta sin cesar- se restringe a lo Maternal (Kristeva 1998: 209).

Esto se relaciona íntimamente con el complejo de Edipo, pues, gracias a la prohibición de desear a la madre impuesta por el Padre, la madre puede continuar siendo objeto de deseo del padre. Si no existiera esta prohibición, el complejo de Edipo nunca se clausuraría y, entonces, la relación entre la madre y el padre sería imposible, ya que la madre sería objeto de 
deseo de su hijo y a la inversa, es decir, el hijo sería objeto de deseo de la madre. El padre, entonces, no tendría cabida y sería desplazado por el hijo.

De esta forma, el indio José habría sido desplazado por la maternidad de su compañera. El objeto de deseo de ella dejó de ser José, ella murió para José; por eso muere en realidad y deja solo a José. En este orden de ideas, la ausencia del objeto de deseo del indio José es la verdadera razón de su angustia, lo que nos lleva de regreso a la cuestión de la melancolía y el duelo.

Vamos por partes. La interpretación de Roland Barthes en torno a la angustia provocada por la ausencia nos resulta muy útil en este momento. El teórico nos explica que esta angustia surge ante una pérdida y un duelo que en realidad ya han ocurrido y se han verificado; es decir, funciona en tiempo retrospectivo, surge ante algo que ya ha pasado. Y es que el duelo, desde Barthes, está implícito en el momento mismo del rapto o del origen del amor (Barthes 1982: 37).

Así, podemos afirmar que el indio José es un sujeto que sufre un duelo ante la ausencia de su compañera. No obstante, en realidad, sabemos que lo que siempre falta es la madre, pues esa es la pérdida primigenia.

En el momento en que se conforma el sujeto, al entrar en el lenguaje gracias a la prohibición primigenia del incesto introducida por el padre (cuando sobreviene la amenaza de castración), el niño pierde la ilusión de completud con la madre, imaginario que estaba cuando el niño se identificaba totalmente con la madre (período del narcisismo primigenio) y no se sabía diferente de ella. Desde el momento de la prohibición, ella va a faltar para siempre. La madre es el objeto que falta y que el sujeto tratará, una y otra vez, de recuperar; intenta siempre regresar a ese estado de completud donde la madre no falta. La falta de la madre motiva el deseo (de alcanzar la completud perdida); por eso, si la completud se alcanza, el deseo se detiene y sobreviene la muerte psíquica. Ese deseo de recuperar el objeto es la pulsión de muerte, que coloca al sujeto en el registro de lo Real, representado en nuestro texto por el grillo, por cuanto constituye una muestra del eterno retorno que siempre es Real. Por eso, el grillo le produce la angustia al indio José y por eso no puede dormir.

\section{Calle melancolía}

Ahora bien, retomando, el indio José es un sujeto melancólico porque sufre el duelo ante la pérdida de su compañera, que en realidad representa la pérdida y la carencia de la madre. En otros términos, la muerte de su compañera le recuerda su imposibilidad de ser uno con su madre y así ser objeto de deseo de su padre, hecho que corresponde al narcisismo primario, cuando tenía la ilusión de completud:

\footnotetext{
La pérdida absoluta en el sujeto de la melancolía lo remite a su imposibiliad de colocarse como objeto amado por el padre (Chacón 1999: 21).
}

Según Laura Chacón, Freud indica que la melancolía sucede cuando el estado de pérdida se vive irrecuperable y el sujeto se identifica con el objeto perdido; por tanto, el sujeto se vive a sí mismo como objeto perdido. Al hacerlo, el sentimiento de pérdida es absoluto, pues el sujeto busca el todo que es irrecuperable: 
Toda pérdida pasa a ser vivida desde el lugar de lo irrecuperable porque el sujeto busca el todo, el sujeto no se resigna a no encontrar el todo (Chacón 1999: 21).

Debido a esto, el sujeto sufre la pulsión de muerte, y la sufre una y otra vez. Por eso, lo Real siempre regresa, porque el sujeto siempre trata de recuperar ese todo que perdió: la completud o el estado de narcismo primigenio en el que estaba totalmente identificado con su madre y no había ni diferencia ni tiempo ni carencia ni deseo. De nuevo, el grillo en el texto es ese Real que regresa intermitente, una y otra vez.

En torno a lo anterior, Laura Chacón explica -a partir de Lacan- que el sentimiento de pérdida no responde al olvido o a la ausencia del objeto amado sino que, más bien, responde a la pérdida del sí mismo identificado en el narcisismo primario con la madre que se ha perdido: toda pérdida remite ineludiblemente a esa primera pérdida de la madre, cuando sobreviene la amenaza de castración. En este sentido, la muerte de la compañera del indio José es sólo el detonante del retorno de esa pérdida de la identificación con la madre, la pérdida del narcisismo primario, que causa el deseo. Por este motivo, es lógico que se considere la melancolía como el estado en el que el sujeto se identifica con el objeto perdido (que en realidad es la madre, aunque suceda cuando se sufre cualquier pérdida) y reconoce que no puede ser objeto de deseo de su padre, porque precisamente la madre se ha perdido y, con ella, ha perdido el todo.

Es claro entonces por qué esta pérdida de la madre y de sí mismo es del orden de lo Real, pues al identificarse el sujeto con el objeto perdido lo que encuentra en su lugar es un vacío, la Nada misma:

\footnotetext{
El sujeto se identifica con lo perdido que se hace presente no como símbolo de la nada, sino como la Nada, es decir, mostrándose como la tierra que acoge al sujeto en su destierro del campo del Otro (Mullet 1999:78).
}

Esa Nada, afuera del campo del Otro, es decir, fuera de lo simbólico, es el agujero de lo Real. Lo que el sujeto encuentra ante la pérdida de sí mismo es el agujero de lo Real y, al no estar en el campo de lo simbólico -es decir en el campo del lenguaje-, no puede nombrar al objeto perdido.

Resulta significativo que el indio José en ningún momento se queje de la ausencia/muerte de su compañera directamente y que ni siquiera la mencione; sabemos de esto por el narrador omnisciente. El indio José se limita a manifestar su soledad y tampoco menciona a su madre o a su padre.

Con respecto a este punto, Freud indica que el sujeto melancólico es incapaz de nombrar el objeto perdido (Mullet 1999: 70); esto porque -en términos lacanianos- lo Real es innombrable, está fuera del lenguaje. Y el objeto perdido (la madre, la completud con la madre y la identificación total con la madre) es del orden de lo Real; por consiguiente, no puede nombrarse. Así, el indio José expresa su soledad, su carencia de alguien con quien hablar, pero no dice que esa carencia surge a partir de la muerte de su mujer, ni tampoco que en realidad se refiere a la pérdida de la madre con la que se ha identificado y, por ende, a la pérdida de sí mismo. Por eso, el indio José se queja de la presencia del grillo.

Volviendo al texto, la pérdida de la compañera detonó en el indio José esa pulsión de muerte y, con ello, sobreviene la amenaza perenne del encuentro con lo Real representado por el grillo. Siguiendo este razonamiento, el indio José -sujeto melancólico y doliente- es amenazado 
por el grillo que no lo deja dormir con el eterno retorno de la pérdida, y estará durante todo el cuento bordeando lo Real, se encontrará al borde del abismo y necesitará, por ende, regresar a lo simbólico para seguir deseando. Pero antes de poder hacerlo, su deseo estará detenido.

Freud explica que el sujeto melancólico produce una parálisis del propio deseo y se da una inhibición, que siempre es autopunición. El indio José sufre de esta inhibición o autopunición:

Entró y le vinieron muchas ganas de ponerse a llorar. Se contuvo para no darle importancia al grillo (Salazar Herrera 1990: 62).

Aunque en el texto el motivo para la inhibición del llanto es restarle importancia al grillo, ésta responde, en realidad, a la autopunición que realiza el sujeto doliente o melancólico como mecanismo de defensa ante el estado absoluto de pérdida, donde lo perdido es él mismo. Esto porque hay una total identificación del sujeto con el objeto perdido, como ya apuntamos, lo que le produce un dolor y una culpa insoportables, ante los cuales siente la necesidad de castigarse. Y es que, según Freud, el sujeto melancólico vive la falta como una culpa.

Sin embargo, ese grillo -al que no quiere darle importancia, pero que le produce tanta angustia, que está en el lugar de su melancolía provocada por la muerte de su compañera y que le recuerda la pérdida del momento de completud con la madre- regresa una y otra vez, eterno retorno de la amenaza del encuentro con lo Real, que surge ante la parálisis del propio deseo. Al detenerse el deseo, el sujeto bordea lo Real y sale de lo simbólico. En esta medida, el indio José se enfrenta con lo Real, representado por el grillo, debido a que su sentimiento de pérdida es absoluto, provocado en apariencia por la muerte de su compañera.

\section{La hoguera sacrificial}

Por otra parte, Jessica Mullet nos dice, a través de las palabras de J. Allouch en Erótica del duelo en tiempos de la muerte seca, que: "El duelo no es solamente perder a alguien (agujero en lo real) sino también convocar en ese lugar a un ser fálico para poder sacrificarlo. Hay duelo efectuado si y sólo si ha sido efectuado ese sacrificio". En esto concuerda Freud en Duelo y melancolía, quien indica -según Mullet (1999: 72-3)- que el trabajo del duelo invita a una cierta liberación.

Según lo anterior, nuestro personaje estaría convocando un ser fálico para llenar el objeto perdido, que en este caso correspondería al rancho, el cual definitivamente desplaza su objeto. Desde la perspectiva del indio José, el rancho no lo quiere y por eso lo sacrificará, quemándolo:

\footnotetext{
¡Este rancho no me quiere!... -repitió casi llorando.[...] Se detuvo, volvió a mirar atrás y contempló un momento el rancho ardiendo.

Su cara se iluminó dos veces. Primero con el resplandor de las llamas... y después con una extraña sonrisa de triunfo (Salazar Herrera 1990: 62-3).
}

Al quemar el rancho, nuestro personaje sufre la liberación. De ahí, su extraña sonrisa de satisfacción. Y gracias al incendio del rancho, escapa al encuentro con lo Real, por lo que la muerte psíquica no sobreviene. 
Ahora habría que preguntarse por qué el rancho simboliza ese objeto fálico, cuyo sacrificio producirá la liberación del sujeto.

Según sabemos, el indio José se queja repetidamente de que el rancho no lo quiere. Esta queja en realidad corresponde a que el padre no lo quiere y esto sucede por la imposibilidad que tiene el sujeto melancólico de ser el objeto de deseo de su padre, aunque ése sea su deseo al identificarse con su madre, a la que ha perdido. En otras palabras, el sujeto melancólico, ante la pérdida, regresa al estado de narcisismo primigenio de absoluta identificación con la madre, donde él pueda colocarse como objeto de deseo del padre; pero esto no sucede porque la madre (y él mismo) corresponde al objeto perdido. Entonces sobreviene la angustia.

En este sentido, la queja del indio José no puede ser más elocuente, pues al decir que el rancho 5 no lo quiere, en realidad quiere decir que el padre no lo quiere. El padre no quiere al sujeto melancólico. Así, el indio José hace una identificación entre el rancho y el padre que lo rechaza. Siguiendo esta idea, es posible, entonces, afirmar que el rancho corresponde a ese objeto fálico que, para Allouch, el sujeto necesita sacrificar con el fin de salir de la melancolía. Sólo así puede elaborarse el duelo, porque la melancolía es la imposibilidad de llevar a cabo el duelo. Es la respuesta a la invitación que -según Freud-el duelo hace hacia la liberación.

Al destruir el rancho, el indio José mata al grillo y así logra superar la amenaza de lo Real, sale del eterno retorno, entra otra vez en el transcurrir del tiempo, es capaz de irse y de regresar a lo simbólico. Se libera y por eso no se suicida ni sufre la muerte psíquica. Y en ese sacrificio fálico, también se sacrifica parte del sujeto, como suplemento. Recordemos que, al fin y al cabo, el sujeto melancólico se ha identificado con el objeto perdido. Se sucede entonces una de las tantas muertes que experimenta el sujeto en el registro de lo Real.

\section{Posludio}

Para concluir nuestro análisis, en el cual transitamos por lo Real -a ritmo del canto persistente del grillo-, vislumbramos el dolor insoportable del sujeto doliente y probamos un poco de la melancolía que puede aquejar a cualquiera a partir de la trágica experiencia de la pérdida. Diremos que sorprende la coincidencia más que asombrosa entre el cuento "El gri1lo" de Salazar Herrera y el discurso del psicoanálisis. Y no podía ser de otra manera, pues el discurso donde lo inconsciente aflora es siempre asombroso.

Esto sólo confirma nuestra tesis del principio: los relatos en Cuentos de angustias y paisajes, además de estar impecablemente narrados, con un estilo bastante particular tomado de la pintura, aparte de que retoman el preciosismo propio del modernismo, cuentan las angustias de muchos personajes. Esto hace que los cuentos pongan en escena las grandes y pequeñas tragedias recurrentes del ser humano común y corriente, cuya psique se bate constantemente entre lo Real, lo Simbólico y lo Imaginario, y nos revelan cómo, de algún modo -a menudo traumático-, éste logra anudar su existencia y su subjetividad.

No es casual -nos parece- que la mayoría de los acercamientos a este texto sean estilísticos: los Cuentos de angustias y paisajes escenifican lo Real, y ante la angustia que esto provoca en el lector, lo que se sucede es el silencio, o más bien el hablar, pero hablar de otra cosa. Claro, esto requiere de mayor análisis y no es por ahora nuestro objetivo responder a preguntas 
externas más acordes con un estudio de la recepción del texto, así que dejaremos este punto sólo como una inquietud.

De esta forma, el relato "El grillo" es el recorrido psíquico del indio José de lo Real a lo simbólico. Gracias a que sacrifica su rancho -objeto fálico, representante del Padre- como último y desesperado recurso para regresar a lo simbólico, logra silenciar el incesante canto del grillo, sortea así el eterno retorno y recupera, por esta vez, el deseo; de ahí su extraña sonrisa de triunfo al mirar el rancho arder. El indio José alcanza su liberación pero a un costo muy alto: la destrucción de su hogar, el cual ya se había desestructurado con la muerte de su compañera, detonante de su estado melancólico, donde imaginariza la identificación con la madre perdida. Y es que la pulsión de muerte es devastadora y si un sujeto la experimenta, puede salir, pero no sin cicatrices, porque en el universo de lo inconsciente siempre se pierde.

\section{Notas}

1. Una versión anterior de este artículo se presentó como ponencia en el I Coloquio de Literatura Costarricense -Álvaro Quesada Soto-, celebrado en mayo del 2004, en la Universidad de Costa Rica.

2. Para poder afirmar esto, se realizó un rastreo de los comentarios, tesis y artículos que se han referido a Cuentos de angustias y paisajes, como la tesis La prosa artística de Carlos Salazar Herrera en Cuentos de angustias y paisajes, de Jorge Andrés Camacho; el libro del mismo autor llamado El estilo de los cuentos de Salazar Herrera; la tesis de Yolanda Brenes La focalización en los Cuentos de angustias y paisajes; así como los artículos publicados en el Repertorio Americano, por Emilia Prieto, Arturo Echeverría Loría y Moisés Vincenzi, con motivo de la publicación del cuentario de Salazar Herrera.

3. Freud proporciona varias definiciones de lo Ominoso para poder desarrollar este tema clave en el psicoanálisis. Nos dice que lo Ominoso, como la palabra en alemán Unheimlich lo indica, es aquello que viene de lo familiar, pero que al mismo tiempo no lo es. También, Unheimlich se define como aquello que no es hogareño, no es familiar, no es doméstico. Es el opuesto de heimlich, íntimo. Así, lo Unheimlich consiste en lo desconocido, o que debió permanecer desconocido y que es innombrable (Freud 1998: 227). El encuentro con lo Real resulta ominoso precisamente porque es aquello que no debe nunca ser reconocido; de hecho, no puede ser nombrado.

4. La cultura china le da una marcada importancia al grillo y lo asume como un triple símbolo de vida, muerte y resurreción, pues pone sus huevos en la tierra, vive allí en forma de larva y luego sale y se metamorfosea en imago (Chevalier 1999: 540). Curiosamente, esto casi se opone por completo al grillo del cuento, en el que éste representaría, como se vio, la amenaza del encuentro con lo Real, la pulsión de muerte y el eterno retorno, a menos que se haga la relación con su simbología de la muerte.

5. El rancho o la casa son semejantes al templo y en este sentido simbolizan el universo mismo, el centro del mundo (Chevalier 1999: 259). Su importancia y su relación con la angustia del indio José queda entonces más clara, pues como centro del mundo indudablemente corresponde a ese objeto fálico que el indio José necesita sacrificar. 


\section{Bibliografía}

Barthes, Roland. 1982. Fragmentos de un discurso amoroso. México: Siglo XXI.

Baudes de Moresco, Mercedes. 1995. Real, Simbólico, Imaginario. Buenos Aires: Lugar Editorial.

Brenes Ovares, Yolanda. 1995. La focalización en los Cuentos de angustias y paisajes. Tesis de Licenciatura: Universidad de Costa Rica.

Braunstein, Néstor. 1993. "La herejía del eterno retorno". En: Braunstein (ed.), 35-57.

(ed.). 1993. Coloquio. El tiempo, el psicoanáilsis y los tiempos. México: Siglo XXI.

Camacho, Jorge Andrés. 1965. La prosa artística de Carlos Salazar Herrera en Cuentos de angustias y paisajes. Tesis de Licenciatura: Universidad de Costa Rica.

1971. El estilo de los cuentos de Salazar Herrera (Ensayo crítico y antología). San José: EDUCA.

Chacón, Laura. 1999. "Un siglo de velocidad: el errar en la melancolía". In\$C.R.ibir el psicoanálisis. Año 6 (9). Enero-Diciembre: 17-23.

Chevalier, Jean y Alain Gheerbrant. 1999. 6a. edición. Diccionario de los símbolos. Barcelona: Editorial Herder.

Echeverría, Loría Arturo. 1947. "Carlos Salazar Herrera: Cuentos de angustias y paisajes". Repertorio americano: 105.

Freud, Sigmund. 1998. 2a. edición. "Lo Ominoso". Obras Completas. Vol. XVII. Buenos Aires: Amorrortu: 217-251.

Kristeva, Julia. 1998. 2a. edición. Historias de amor. México: Siglo XXI.

Mullet, Jéssica. 1999. "Los rostros en la melancolía”. In\$C.R.ibir el psicoanálisis. Año 6 (9). Enero-Diciembre: 69-80.

Prieto, Emilia. 1947. "Con Salazar Herrera”. Repertorio americano: 109.

Salazar Herrera, Carlos. 1990. Cuentos de angustias y paisajes. San José: Editorial El Bongo.

Vincenzi, Moisés. 1948. “Cuentos, por Carlos Salazar Herrera”. Repertorio americano: 74-75. 